\title{
Implementation of adaptive fuzzy controller on the variable speed wind turbines in comparison with conventional methods
}

\author{
Somayeh Abdolzadeh ${ }^{1}$, Seyed Mohammad Ali Mohammadi ${ }^{2}$ \\ ${ }^{1}$ M.Sc. Student of Islamic Azad University, Science and Research Branch of Sirjan \\ ${ }^{2}$ Assistant Professor of Shahid Bahonar University of Kerman
}

\begin{abstract}
This paper introduces a linear structure of wind turbine, operator and the pitch angle controller. Then, a new method of adaptive fuzzy on the variable speed wind turbines was provided and it was compared with PID and Fuzzy Logic Controller and the simulation results were analyzed. So when the results of each simulation using PID and Fuzzy controllers and adaptive fuzzy PID controllers provided, the observed advantages and disadvantages of the rotor speed and wind turbine power can be introduced. It can be seen that in PID method the high overshoot is discussed as a disadvantage while it is overcome by using fuzzy controller and overshoot will decrease. The time of reaching to a sustained speed increases slightly and in adaptive fuzzy PID controller, the less overshoot has provided a good and effective performance for system response. The use of adaptive fuzzy PID controller causes the system does not have any steady-state error and at all moments of time, the response rate is better than PID and fuzzy controller. The importance of the amount of overshoot and rate fluctuations is that by reducing these parameters in addition to reducing the cost of preventive care, maintenance and depreciation, the fluctuations in electricity generated by induction generator also greatly reduced.
\end{abstract}

Keywords: variable speed wind turbine, the blade control, fuzzy controller, the controller PID 


\section{Introduction}

According to the forecasts, it is expected that by 2050 global demand for energy grows up to 3 times. At least 15 to 20 percent of global energy demand will be met directly by new and renewable energy sources [1]. In the year 2011, compared to the end of 2009, the rapid growth of $50.532 \%$ can be seen in the volume of energy intake (MW) of wind turbines in the world that the current leaders of the movement are advanced industrial countries [2]. The use of Wind energy is on the rise because it is clean, but the truth about wind power is that wind energy is expensive and for economic use, it is necessary to minimize the occurrence of errors in it [3]. The first wind turbines connected to the power network was built on the Orkney Islands in Great Britain in 1951 [4]. Production of nuclear and fossil power and other energies which are harmful for the environment, peace and human welfare, must be replaced with better methods, it means that they should turn into the form of available renewable energy in the environment [5]. One of the factors which cause tensions and amortization in wind turbines is fluctuations and high overshoot. Because the axis of the wind turbine generator is coupled with the generator shaft, the speed fluctuations will transfer to the generator so the amortization of generator and wind turbine will increase. For this reason, preventive care and maintenance for the turbines increases. Due to the high cost of wind turbines and setting up them in difficult access regions, such a large depreciation will involve high costs, which shows the importance of the speed control of wind turbines. If you do not control the wind turbine fluctuations, fluctuations in electrical frequency can be seen in the induction generators, so with less money, the speed of the wind turbine can be controlled to a large extent. So in this article, after the introduction of wind turbines and their linear model, three types of controller consist of fuzzy, PID and adaptive fuzzy PID to control the speed and overshoot of the wind turbine will be introduced. The results of its simulation are shown using Simulink /
Matlab software. The results showed that adaptive fuzzy PID controller has provided a good and effective performance for system response. The paper consists of 6 parts; the first part is an introduction to wind energy, the second part introduces wind turbine, the third part introduces the dynamic relationship of wind turbine, in the fourth part operator model and wind turbine controllers are discussed, in the fifth part simulation and final part VI is the conclusion.

\section{The introduction of wind turbines}

In most wind turbine, rotor and wind turbine generator are the main control method and general model of Figure 1 can be considered to understand the relationship of controllers with the other components of the wind turbine system.

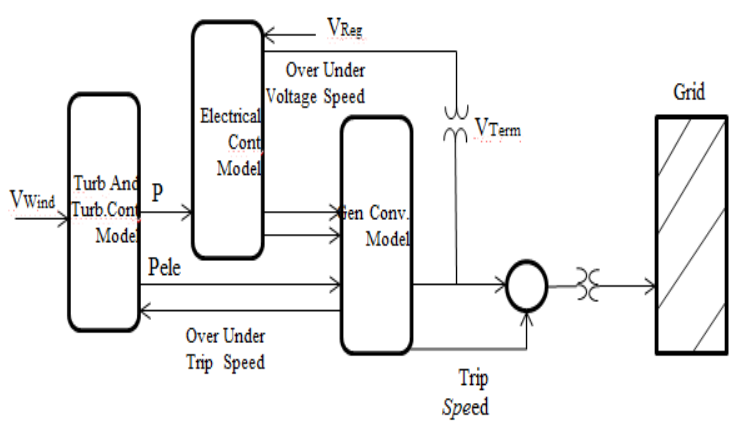

Figure 1: The general model of wind turbines and their interactions

The general model of a wind turbine includes a generator / converter model which is located between wind turbine generator (WTG) and grid and it is used to convert mechanical power to electrical power and to determine the rotor speed. This model also includes a wind turbine as an electromechanical system for converting the kinetic energy of wind into electricity. It is a simple example of a very complex electromechanical system. The model shows the active and reactive power which is transfered to the power system based on input from the turbine model and condition of the power 
system [6]. In the model shown in Figure 2, wind speed model can be used for generating a wind signal that can be applied to the rotor, rotor model is used to convert the kinetic energy contained in the wind to the mechanical power can be applied to the generator; The rotor speed controller is used for deriving a power set point from the rotor speed versus generator power control characteristic,based on the actual rotor speed; pitch angle controller is used for changing the blade pitch above nominal wind speed preventing the rotor speed from becoming too high; voltage controller is used for keeping the terminal voltage near its reference value; protection system is used for limiting the converter current and for switching off the wind turbine when terminal voltage or grid frequency deviation exceed a specified value for a given time. In Fig. 2, the turbine model and its controllers are depicted.

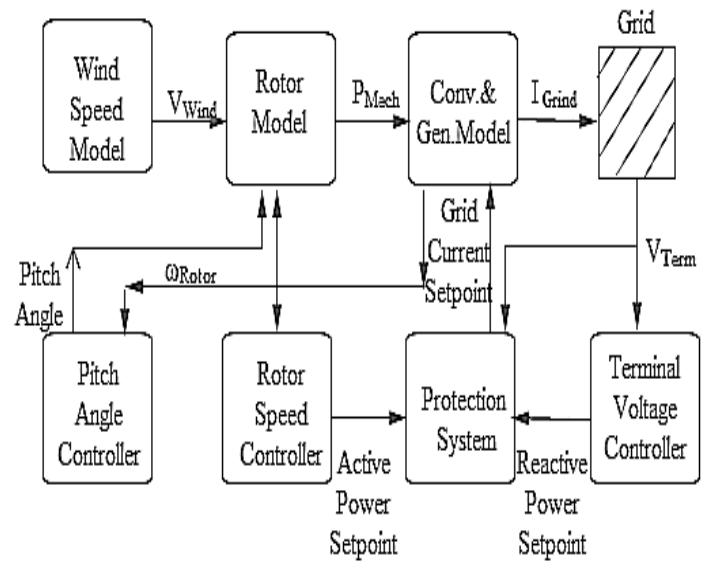

Figur. 2: the turbine model and its controllers

\section{The relationships of the dynamic model of wind turbine}

The main dynamics of the variable speed wind turbine are obtained by the following mathematical model:

$$
\begin{aligned}
& J_{t} \omega_{t}=T_{w}-T_{m} \\
& J_{t}=\rho_{\mathrm{a}} . I
\end{aligned}
$$

Where $\mathrm{J}_{\mathrm{t}}$ is the moment of inertia of the turbine rotor which is obtained from the equation (2), I is the moment of inertia, Qa is regional density of the rotor axis, which is obtained by multiplying the length in the bulk density [7], $W_{t}$ is Angular velocity of turbine axis, $T_{m}$ is the necessary mechanical torque to turn the generator, and it is obtained by the equation (3) [8]:

$$
\mathrm{T}_{\mathrm{m}}=\frac{\rho \mathrm{ARC}_{T} V_{W}^{2}}{2}
$$

Where $\varrho$ is air density, A is the area swept by the blades and $C_{T}$ is torque coefficient, which obtained by the following equation $C_{T}=C_{p} / \lambda$ where $\lambda$ is the ratio of the velocity of at the tip of the blades and it is the ratio of the angular velocity of the rotor to the linear wind speed at the tip of the blades ( $\left.\lambda=\frac{\omega_{t} R}{V_{w}}\right), \mathrm{R}$ is the radius of the wind turbine rotor and $V_{w}$ is the wind speed.

The wind turbine is determined by the power coefficient curve $\left(C_{p}\right)$ as a function of the speed of the blade tip $\lambda$ and pitch angle ( $\beta$ or $\theta$ ). The nonlinear dynamic model of turbines around the operating point is converted to the linear form of the following equation [8]:

$$
J_{t} \Delta \omega_{t}=\gamma \Delta \omega_{t}+\zeta \Delta V_{W}+\delta \Delta \beta
$$

Where $\zeta, \delta$, and $\gamma$ are linearization coefficients and here $\Delta \mathrm{V}_{\mathrm{w}} \Delta \omega, \Delta \beta$ represents a deviation from the operating point of $V_{\text {wop }}, \beta_{0}$

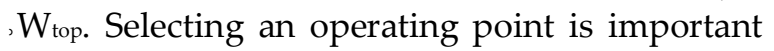
for maintaining the aerodynamic stability in the system. Establishment of the blade, $\omega$ and wind speed are fixed values which are selected suitably for turbine, then using the Laplace transform function, the equation is obtained as follows:

$$
J_{t} s \Delta \omega_{t}=\Upsilon \Delta \omega_{t}+\xi \Delta V_{W}(s)+\delta \Delta U(s)
$$

The speed of the turbine rotor axis is equal to:

$$
\Delta \omega_{t}=\left[\frac{\xi}{J t} \Delta \mathrm{V}_{W}(s)+\frac{\delta}{J t} \Delta \mathrm{U}(\mathrm{s})\right] \cdot \frac{1}{S-D}
$$

Equation (6) represents the linearized model of a wind turbine; a block diagram of this model is shown in Figure 3 [8]. 


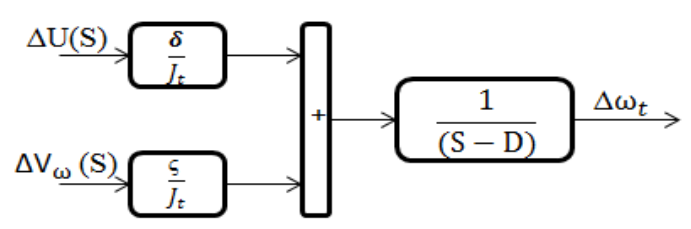

Figure 3: a block diagram of the linearized model of a wind turbine

\section{Operator model and wind turbine controller}

Here the control of input speed to selfstimulate, induction generator that moves by the wind turbine, is done through the control of wind turbine components. For this purpose, the linearized dynamics model of the wind turbine is used. The PID controller is used to control the speed of the turbine rotor, in practice, to do this, in addition to the PID controllers; the operator also must be adjusted until turbine blades placed in the proper position according to the input commands of the operator. the operator can, for example, be a permanent magnet DC motor which is presented in the block diagram of Figure 4, where Ua (s) is the input Laplace and Uo is the output Laplace of the pitch angle, $\mathrm{K}_{\mathrm{m}}$ is the fixed interest $\tau_{\mathrm{m}}$ is the time constant of the permanent magnetic motor [8].

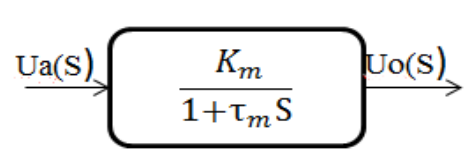

Figure 4. Block diagram of the operator

Speed controller is shown in Figure 5. It is used to control the rotor speed of the wind turbine, where $\Delta \mathrm{W}_{\mathrm{T}}$ (s) is the input speed of rotor (error signal) and $\Delta \mathrm{U}_{\mathrm{c}}(\mathrm{s})$ is the changes in the output pitch angle.

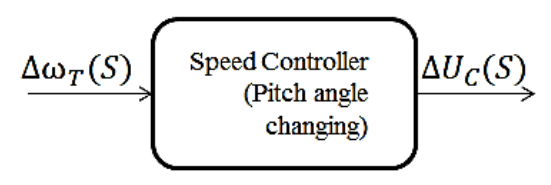

Figure 5. Block diagram of the speed controller
Therefore, if the mentioned models which they are correspond to the controller and operator combined with a dynamic linearized model of the wind turbine, a general model of wind turbine speed controller is obtained as shown in figure $6[6,8]$.

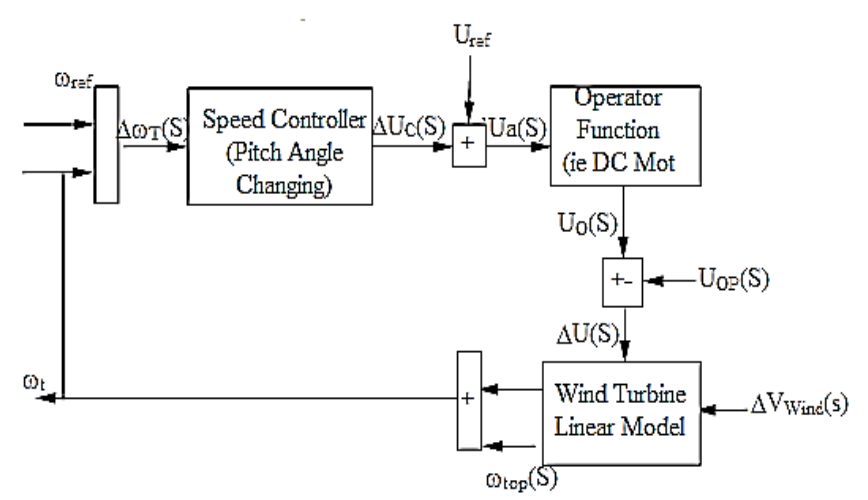

Figure 6. Block diagram of the speed controller system of the wind turbine

\section{Simulation}

Simulation is one of the most basic steps in designing a system because at this stage it is considered whether the system is able to meet all or part of the design criteria or it needs a better plan for better performance. The simulation of a real system using a mathematical model is done by various computer softwares, one of the most common softwares, especially in the field of control engineering is Simulink because it is user-friendly and simple, and in addition, its various tools boxes exempt the user from writing long commands. Here, this software is used for simulating the wind turbine system.

\section{Simulation of the linear model of the wind turbine with PID controller}

Figure 7 shows a simulation block diagram of the rotor speed controller and power of the wind turbine in MATLAB software. The PID controller parameters should be adjusted to achieve optimum performance. PID controller parameters are represented in Table $1[8,9]$. According to these values, the simulation results will be shown. 


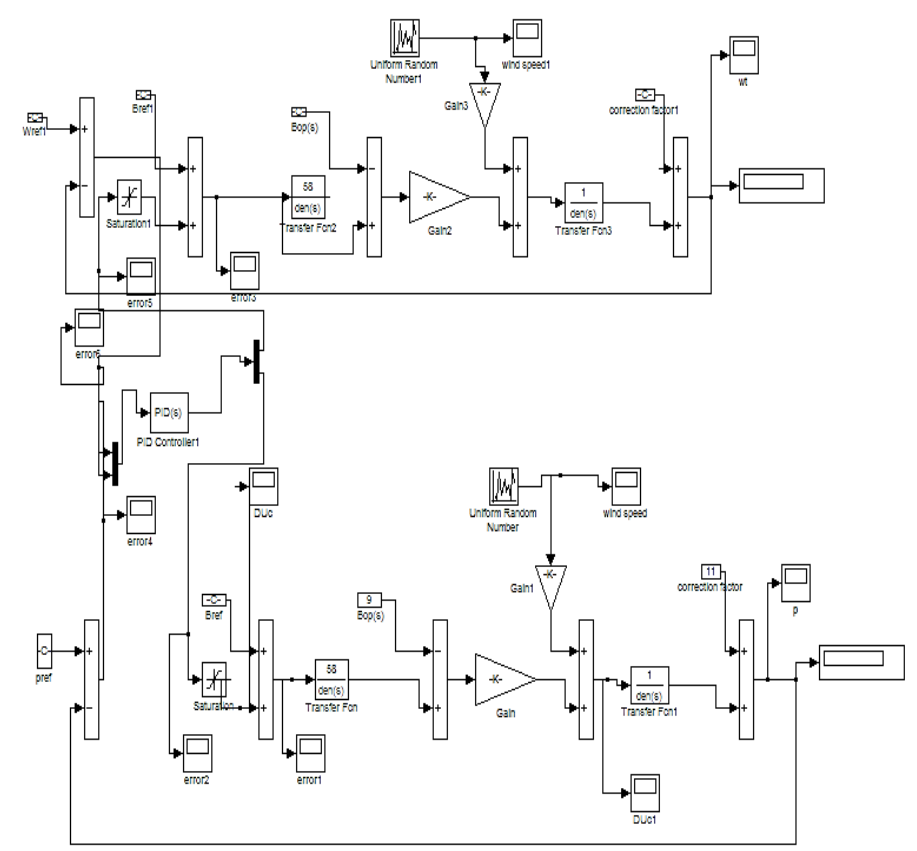

Figure7. Block diagram of PID controller, rotor speed and wind turbine power in the MATLAB / SIMULINK software

Table 1. PID controller parameters [10]

\begin{tabular}{|c|c|c|}
\hline Parameter & Symbol & Value \\
\hline Proportional Term & KP & 40 \\
\hline Integral Term & KI & 12 \\
\hline Derivative Term & KD & 1 \\
\hline
\end{tabular}

\section{Simulation of the wind turbine linear model with fuzzy controller}

Figure 8 shows simulation of the rotor speed control of a wind turbine using fuzzy method.
Membership functions of input error are shown in Figure 9 and membership functions related to the changes in input error are shown in Figure 10. Figure 11 shows the output membership function and Figure 12, as a three-dimensional figure shows the fuzzy rules based on the values of input and output membership functions. Table 2 represents the fuzzy rules used for fuzzy inference in the fuzzy controller [10, 11].

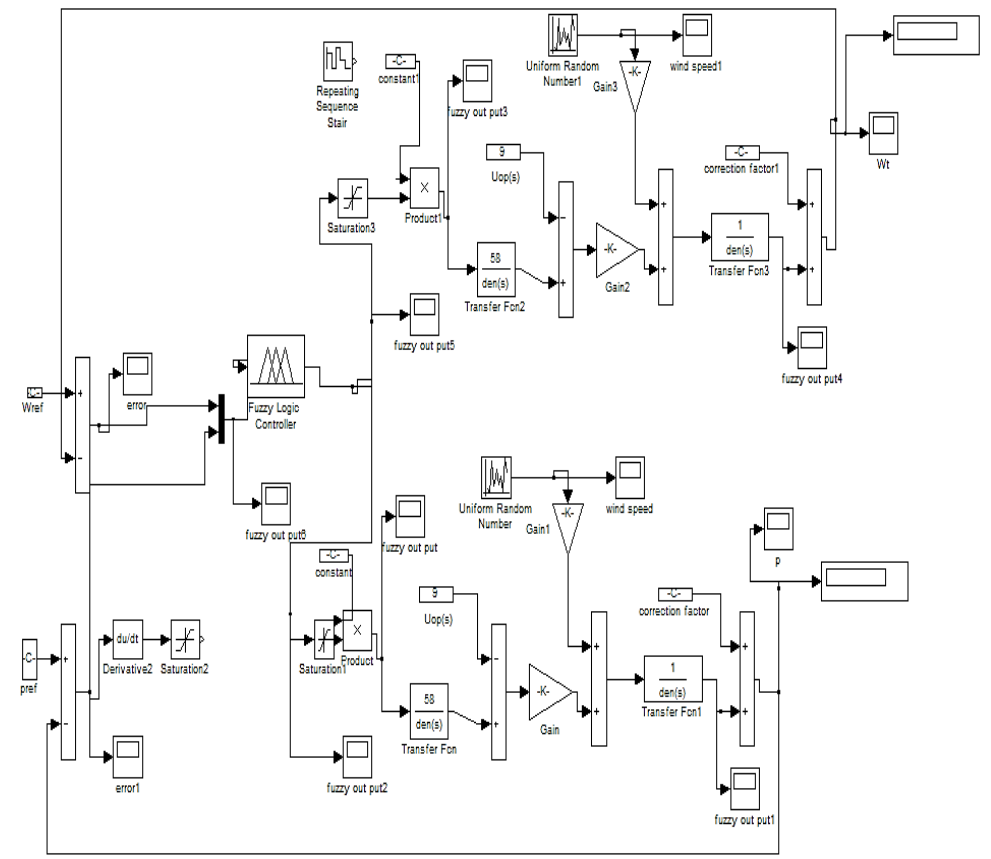

Figure 8. Block diagram of the fuzzy controller of the rotor speed and wind turbine power 


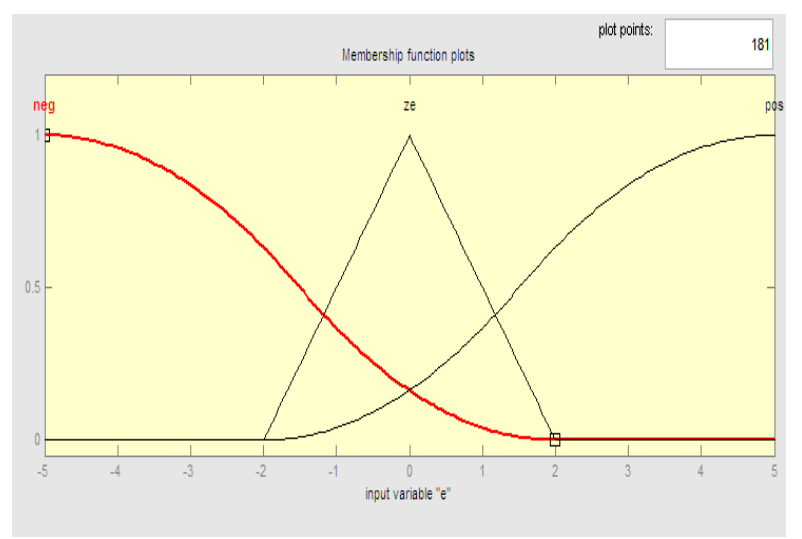

Figure 9. Membership functions of input error

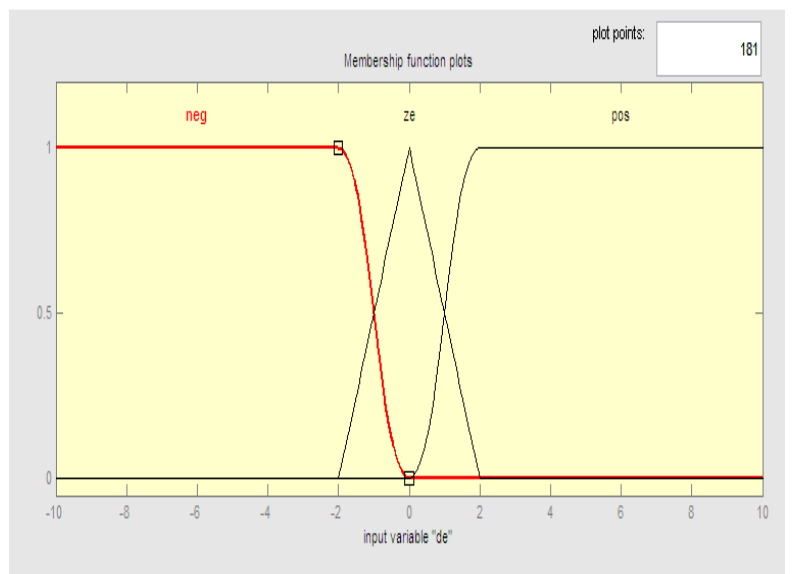

Figure 10. Membership functions related to changes in input error

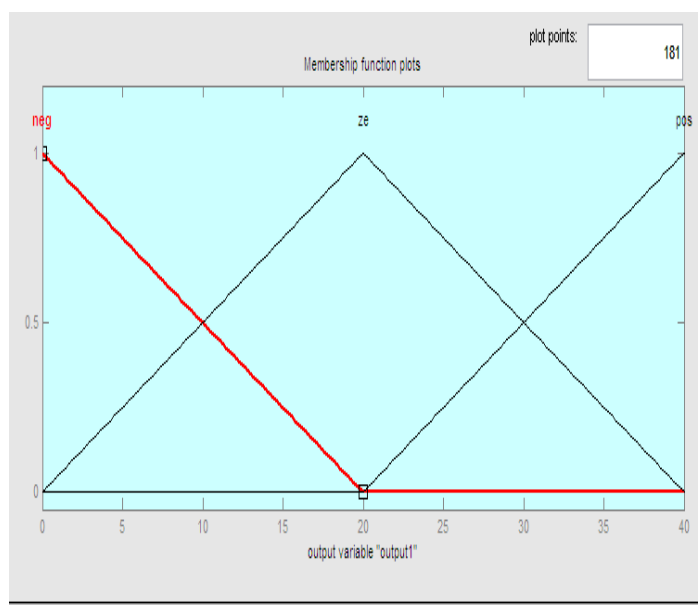

Figure 11. Membership functions of the output variable

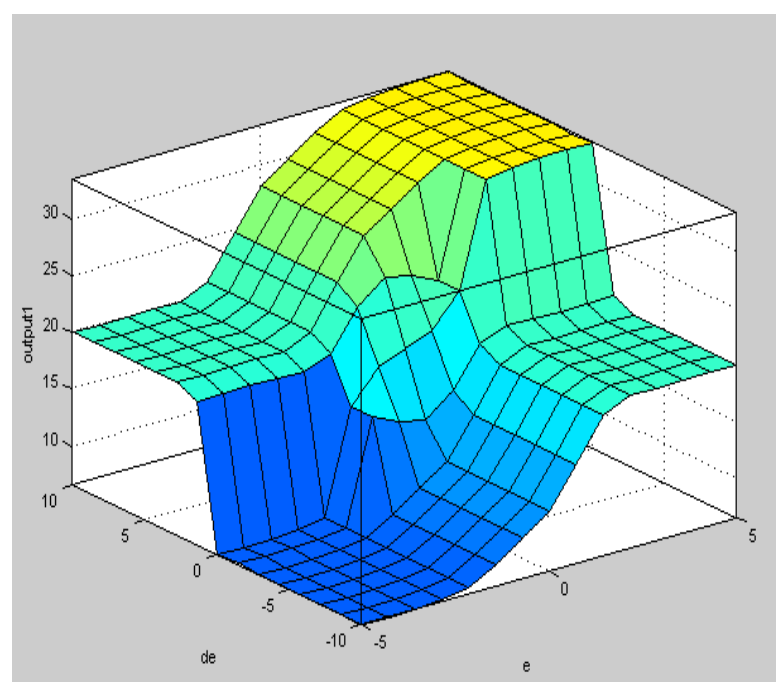

Figure 12. Three-dimensional diagram representing the relationship between error membership functions and error changes with output of fuzzy controller

Table 2. The rules used in the fuzzy controller

1. If (e is neg) and (de is neg) then (outputt is neg) (1)
2. If (e is neg) and (de is ze) then (outputt is neg) (1)
3. If (e is neg) and (de is pos) then (outputt is ze) (1)
4. If (e i z ze) and (de is neg) then (outputt is neg) (1)
5. If (e is ze) and (de is ze) then (outputt is ze) (1)
6. If (e is ze) and (de is pos) then (outputt is pos) (1)
7. If (e is pos) and (de is neg) then (outputt is ze) (1)
8. If (e is pos) and (de is ze) then (outputt is pos) (1)
9. If (e is pos) and (de is pos) then (outputt is pos) (1)

\section{Simulation of the linear model of} wind turbine using fuzzy adaptive PID controller

Basically, fuzzy systems are knowledge-based systems and the heart of a fuzzy system is a knowledge base that is made up of if-then fuzzy rules. Generally, the use of fuzzy controllers is classified in two forms:

- The traditional PID controller is determining online in various operating conditions, then the control signal is calculated and applied to the system.

- Considering the different working conditions, the control signal is calculated directly based on knowledge-based fuzzy inference engine and applied to the system. 
Coefficients of PID controllers are adjusted at the beginning of the process and they are fixed during it. In systems with variable dynamics, constant coefficients do not lead to satisfactory results so the comparative method is necessary to adjust the controller's coefficients. The fuzzy controller is a right choice to adjust the online PID. In fuzzy adaptive controller, the creation of the fuzzy controller is online, in other words, simultaneously with the operation of the system, the fuzzy controller is modified so that optimal control process goes. The fuzzy adaptive PID structure is shown in Figure 13 and Figure 14 shows the structure of the fuzzy PID controller.

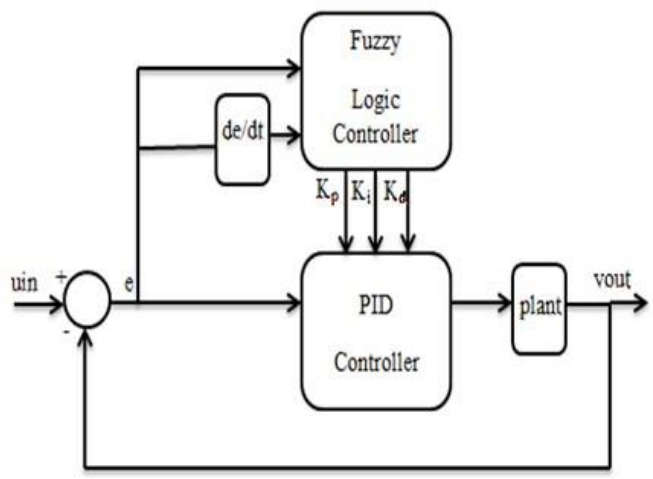

Figure 13: Structure of fuzzy adaptive PID controller

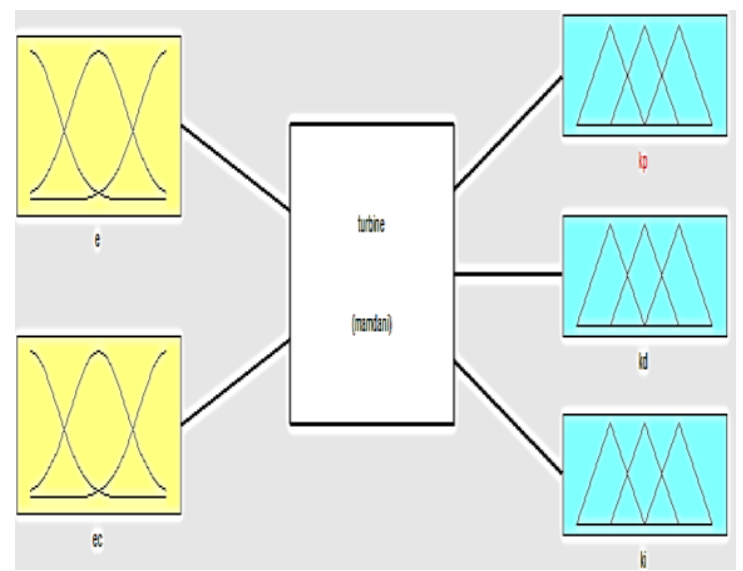

Figure 14: Simulink block diagram of PID fuzzy

The results of the simulation of fuzzy, PID and fuzzy adaptive PID controllers to control the rotor speed and wind turbine power using SIMULINK / MATLAB software

Figure 15 shows the applied wind speed to the wind turbine. In this figure the wind velocity is considered as a random curve. As shown in
Figure 15, the wind speed has a high fluctuation and its amplitude and frequency is infinitely variable. This curve is obtained from a random function so its maximum and minimum level can be adjusted, but when and how its amplitude changes are random.

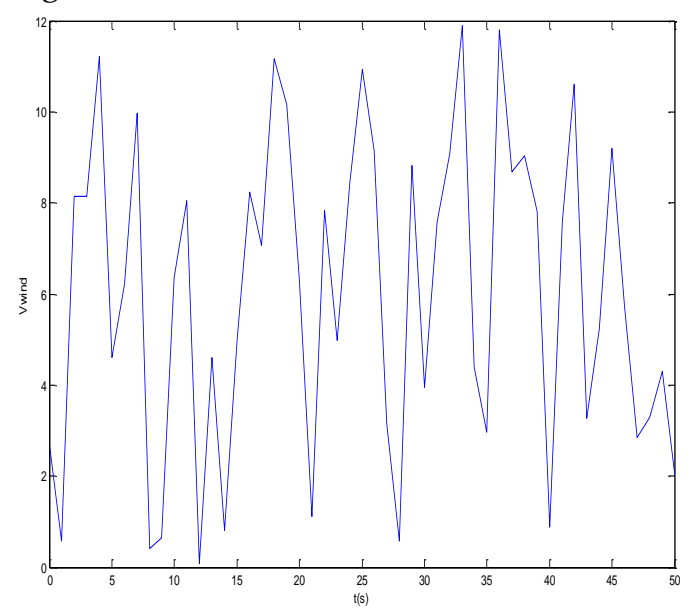

Figure 15: Wind speed applied to the wind turbine

Figure 16 shows the curve for simulation of PID, fuzzy and fuzzy adaptive PID controllers. The curves represent the output speed of the rotor and the power of a wind turbine. As specified in the figure, the use of PID controller will be led to high overshoot in speed and also fluctuations are observed around the stable speed. The fuzzy controller is used to control the speed and power of the wind turbine. The advantage of this controller is the absence of overshoot in speed curve, power and reducing the fluctuation range after reaching steady state. Compared to the PID controller, the settling time is a little more and fuzzy adaptive PID controller provides good performance and effective response for the system. The use of fuzzy adaptive PID controller causes that the system does not have any steady-state error and in all the time of speed, the response is better than PID and fuzzy controllers. Figures 16 and 17 show the results of the simulation and Table 3 shows the parameters used for the comparison.

Table 3: the parameters used for the comparison.

\begin{tabular}{|r|c|c|}
\hline Control & Rise time & Settling time \\
\hline PID & 0.00725 & 0.0712 \\
\hline Fuzzy & 0.861 & 0.483 \\
\hline AF- PID & 0.00698 & 0.0127 \\
\hline
\end{tabular}




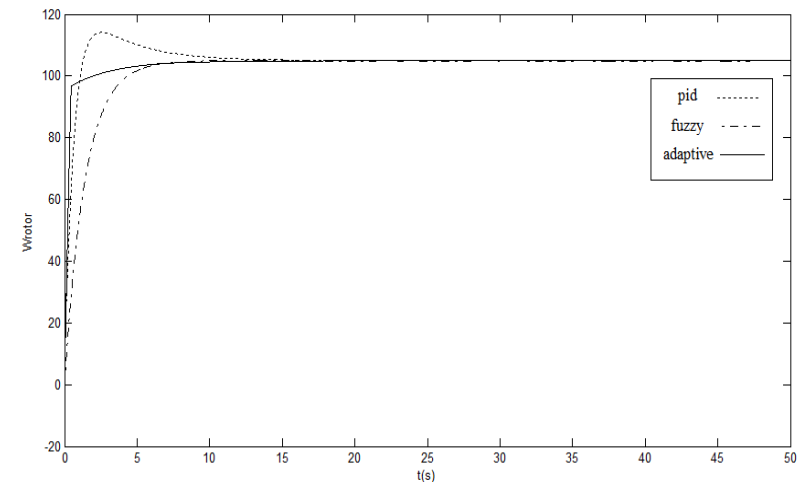

Figure 16: The rotor output speed of the wind turbine

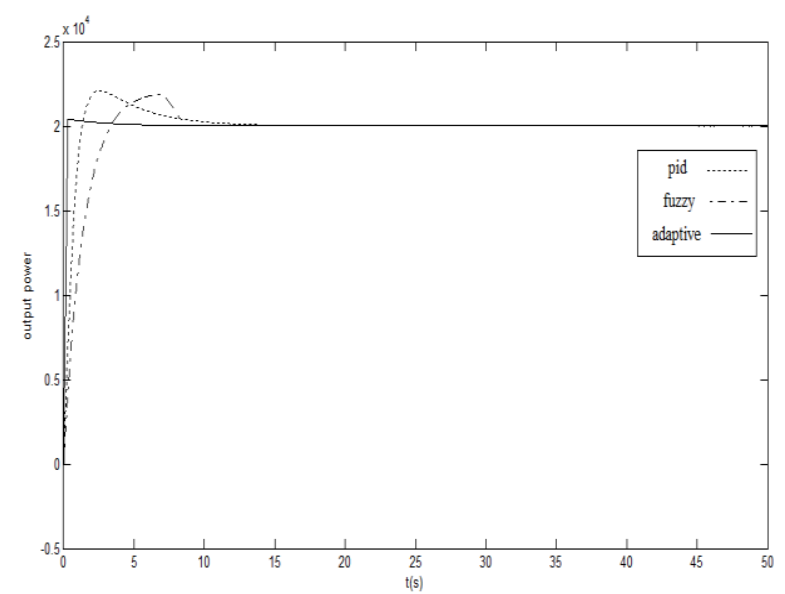

Figure 17: The output power of the wind turbine

\section{Conclusion}

In this paper, the linear model of wind turbine, wind turbine speed and power controllers were introduced. For this purpose, linear model of wind turbines with PID controller, fuzzy controller and adaptive fuzzy PID controller was implemented in a simulation environment of Matlab software. This comparison was based on the performance impact of PID, fuzzy and adaptive fuzzy PID controllers on the output power and speed of the wind turbine axis. In this process, the desired characteristics to compare are the amount of overshoot, the maximum speed of the rotor relative to the reference value and velocity fluctuations in a position to reach a steady state. The importance of checking the output speed of wind turbine axis is because of the fact that the wind turbine axis is coupled with the generator shaft, so the speed fluctuations will transfer to the generator. As a result, if the produced electricity is not controlled, then fluctuations will be observed in the frequency of it in induction generators. While with a lower cost in order to control the speed of the wind turbine, this phenomenon can be controlled to a great extent. In addition the large and sudden fluctuations in axes will increase the depreciation of the wind turbine and generator. For this reason, setting up them in difficult accessible regions, has a large depreciation cost so the speed control of wind turbines is important. Finally, the comparative results can be obtained with respect to all simulation results presented in this section. Fuzzy and Adaptive fuzzy PID controllers have a less overshoot compared to the PID controller and also fluctuations in wind turbine rotor speed in them is less than PID controller. In the adaptive fuzzy PID controller compared to the PID and fuzzy controllers, the settling and rise time is less so better response in transient and stable state and also a good and effective performance for system response will be provided.

\section{References}

H. H. El-Tamaly, A. A. E. Mohammed. "Modeling and simulation of photovoltaic/wind hybrid electric power system interconnected with electrical utility", IEEE Conf., 12th International MEPCON, PP. 645-649, 2008.

The World Wind Energy Association. "Half-year report 2011", WWEA Trans., Germany, PP. 17,2011 .

V. Lesic, M. Vasak, N. Peric, T. Wolbank, G. Joksimovic. ."Fault tolerant control of a blade pitch wind turbine with inverter fed generator", IEEE Conf., International Symposium on Industrial Electronics(ISIE), Vol. 1, No. 1, , PP. 2097-2102 , Aug-2011.

James Blyth Oxford Dictionary of National Biography,Oxford UniversityPress,etrieved10_09,2009

Swedish Energy Agency, Climate report, Swedish Energy Agency, Tech .Rep, 2002.

J. G. Slootweg, S. W. H. D. Haan, H. Polinder, W. L. Kling, . "General model for representing variable speed wind turbines in power system dynamics simulations", IEEE Trans., Power Systems, Vol. 18, No. 1,PP. 144-151, 2003. 
G. L. Johnson. "Wind energy systems", Book, Manhattan, KS, 2006.

F. A. Abbas, M. A. Abdulsada, F. R. Abusief. "Speed control of wind turbine by using PID controller", Eng. \& Tech. Journal, Vol. 29, No. 1, , PP. 65-71, 2011.

M. Hand, "Variable speed wind turbine controller systematic design methodology- a comparison of non linear and linear model based designs", NREL Report No. TP-50025540, National Renewable Energy Laboratory, July1999.

M. Namazov, O. Basturk. “DC Motor Position Control Using Fuzzy Proportional-rivative Controllers with Different defuzzification Methods", Turkish Journal of Fuzzy Systems (TJFS) Trans., Vol.1, No.1, PP.36-54, May2010.

M. F. Rahmat, M. M. Ghazaly.. "Performance Comparison between PID and Fuzzy Logic Controller in Position Control System of DC Servomotor", Journal Technology of Malaysia Technology University, Vol.1, No.1, PP.1-17, 2006. 